Int. J. Electrochem. Sci., 13 (2018) $621-630$

\title{
Influence of Electrodeposited Ni-Mo Alloy on Hydrogen Evolution Reaction at Nickel Foam Cathode
}

\author{
Tomasz Mikolajczyk*, Boguslaw Pierozynski \\ Department of Chemistry, Faculty of Environmental Management and Agriculture, University of \\ Warmia and Mazury in Olsztyn, Plac Lodzki 4, 10-727 Olsztyn, Poland \\ *E-mail: tomasz.mikolajczyk@uwm.edu.pl
}

doi: $10.20964 / 2018.01 .68$

Received: 5 October 2017 / Accepted: 22 November 2017 / Published: 16 December 2017

This communication covers an electrochemical investigation of hydrogen evolution reaction (HER), studied at unmodified (pure) $\mathrm{Ni}$ foam and $\mathrm{Ni}$ foam modified by MoNi alloy deposit. The quantity of electrodeposited Mo on nickel foam was derived by scanning electron microscopy (SEM) technique, combined with Energy Dispersive X-Ray spectroscopy (EDX) analysis. Kinetics of the HER were studied at room temperature in $0.1 \mathrm{M} \mathrm{NaOH}$ for the cathodic overpotential range of $100-400 \mathrm{mV}$. The electrochemical parameters for examined catalyst materials were recorded based on a.c. impedance spectroscopy and Tafel polarization techniques.

Keywords: Nickel foam; HER; MoNi alloy; Electrochemical impedance spectroscopy

\section{FULL TEXT}

(C) 2018 The Authors. Published by ESG (www.electrochemsci.org). This article is an open access article distributed under the terms and conditions of the Creative Commons Attribution license (http://creativecommons.org/licenses/by/4.0/). 